\title{
The attitude of Greek student nurses toward euthanasia
}

\author{
Nick A. Bakalis ${ }^{1}$, Nanouri Filippia ${ }^{2}$, Ntzoufra Maria ${ }^{3}$, Panagiotis Kiekkas $^{1}$ \\ 1. Nursing Department, Technological and Educational Institute of Western Greece, Patras, Greece. 2. University General \\ Hospital of Patras, Patras, Greece. 3. Institution of Social Insurances, Patras, Greece. \\ Correspondence: Nick A. Bakalis. Address: Nursing Department, Technological and Educational Institute of Western \\ Greece, Egnatias 13 - Actaion Patras, TK 26500, Patra, Greece. Email: nikosbakalis@teipat.gr
}

Received: August 4, 2013

DOI: $10.5430 /$ jnep.v4n1p237

\section{Abstract}

Purpose: Although the focus, on euthanasia, is often exclusively on the involvement of physicians, the involvement of nurses is also given much attention. The aim of the research was to determine and compare the attitude of Greek student nurses toward euthanasia throughout the duration of pre-registration nursing education.

Design: Descriptive study was used in order to determine and compare the attitude of Greek student nurses toward euthanasia.

Method: A valid and modified questionnaire was used, the Frommelt Attitude Toward Care of the Dying (FATCOD), for data collection. The sample constituted of 599 students.

Results: The majority of students evaluated their knowledge in euthanasia as 'low'. Most students report that the nursing education prepares them from 'few' to 'not at all' for euthanasia. The students were negative about the legalisation of euthanasia in Greece. The most important factors that influence their decision about euthanasia were patients' decision, the department protocols and personal belief.

Discussion and Conclusions: Although the cultural context is a significant issue in euthanasia, nurses professional rights in Greece should be modified and the educational programs need to be added with courses which will provide students nurses with stimuli and critical thinking abilities.

Implications for Practice: Nurses should have the appropriate scientific and moral knowledge and skills to cope with the complicated and continuous clinical-ethical dilemmas.

\section{Key words}

Euthanasia, Nursing student, Ethical dilemmas, Greece

\section{Introduction}

Euthanasia is a Greek word and it emanates from two contradictory words 'eu' and 'death', which means 'good death'. Drosou and Kotrotsu ${ }^{[1]}$ describe euthanasia as the acceleration of a person's death, when death is certain, in order not to suffer, with or without person's consent. Euthanasia is reported mainly in patients who have complete mental clarity and psychological balance, elements that allow patients to make this important decision. Euthanasia is not reported in babies 
with special needs ${ }^{[2]}$ in older people with mental health problems ${ }^{[3]}$ or in individuals with psychological problems because then it is reported as homicide ${ }^{[4]}$.

\section{Historical background of euthanasia}

In ancient Greece, euthanasia was imposed by the state and applied to people who were suffering or for mercy. Babies, children, adults and older people with chronic incurable diseases did not have a place in the family of many citizens. Spartiates threw not only the criminals and captives of war in the gulf of Kaiada and Eurota, but also the ill babies or even old men with chronic incurable diseases ${ }^{[1]}$. In Roman years, Balerios Maximos wrote that, in Marseille, a special centre maintained a poisonous drink, known as koneio, that granted the incurable sick, the wish to terminate their lives without pain ${ }^{[5]}$. However, in Europe, the medieval years, euthanasia was considered a serious sin and attempting suicide was punished. Towards this, the Christian teaching of the inviolability of human life contributed ${ }^{[6]}$.

In recent years, more philosophers and doctors are in favour of euthanasia, with the condition of patient consent. Physician Aid-in-Dying (PAD), or assisted suicide, is legal in the states of Washington, Oregon, and Montana in the United States ${ }^{[7]}$. The key difference between euthanasia and PAD is the person who administers the lethal dose of medication. Euthanasia entails the physician or another third party administering the medication, whereas PAD requires the patient to self-administer the medication and to determine whether and when to do this ${ }^{[8]}$.

\section{Types of euthanasia}

The literature reports two types of euthanasia ${ }^{[9]}$. Each type has its own characteristics and particularities. More precisely, in 'active' euthanasia doctor acts to cause the death of patient ${ }^{[10]}$. Although the administration of the lethal medication is usually carried out by a physician, it is sometimes delegated to a nurse. For instance, $21 \%$ of Dutch specialists stated that nurses sometimes administer the lethal medication under their supervision ${ }^{[11]}$. In the same study, Dutch GPs stated that the lethal medication was administered by a nurse in $4 \%$ of the cases, and in 3\% of cases for Dutch hospital physicians. One study showed that the percentage of nurses in South Australia who ended the life of a patient in an active manner at the request of a physician was $5.4 \%{ }^{[12]}$. A Greek study showed that almost one third of nurses $(23 \%)$ have been asked by the physician to administer the lethal medication, and of these, $85 \%$ had complied with the request ${ }^{[13]}$.

'Passive' euthanasia concerns the challenge of 'a good death' with the withdrawal of medication, which is essential for patients to maintain in life ${ }^{[14]}$. There is no ethical or legal distinction between withholding or withdrawing treatments, though the latter may create more emotional distress for the nurse and others involved. The American Nursing Association Code for Nurses provides guidance for ethical conduct and explicates the values and precepts of the profession ${ }^{[15]}$. It is in the context of the Nursing Code that nurses make ethical judgments and discharge their responsibilities. Unlike doctors' ethics, nurses are more concerned with the personal aspect of patient care. For them, it is important that they establish a personal relationship with the patient that will allow them to provide the best possible care.

\section{Euthanasia in various countries}

France, in November 2004, has recognized by law the right of patients to passive euthanasia. In the United Kingdom, the double result rule is in effect. This means that health care professionals is legal to give pain-killers such as morphine, with intention to relieve patients' pain ${ }^{[16]}$. The higher court of United States published a decision that founded the constitutional right to 'help with comfort and care' ${ }^{[17]}$.

In Switzerland, there is one of the four clinics in the world, Dignitas, which accepts patients from various countries with the purpose of terminating their lives according to the patients' wish ${ }^{[18]}$. Holland, Belgium and Luxembourg have legalised euthanasia ${ }^{[5]}$. Uruguay has approved the "right to die". Switzerland and Germany legalised assisted suicide ${ }^{[3]}$. Finally, in Greece, all types of euthanasia are illegal and are punished by Greek law with heavy penalties ${ }^{[19]}$. 


\section{Opinions with regard to the euthanasia}

\section{Religious opinions}

Euthanasia, in the light of Christian ethics, is non-ethical, because it contravenes the 6th command of the Mosaic Decalogue. Christian ethics teach that only God is the Lord of life. It is not permitted either to end your own life or the life of another ${ }^{[20]}$. Also, for Christians, illness can have a deeper meaning in that, it can be an opportunity to show patience and dignity in the face of suffering ${ }^{[21]}$.

\section{Moral opinions}

The mission of law is not to regulate the daily actions of doctors but to prevent unacceptable practices. The 'proposal' that euthanasia is a solution to biological problems is considered very dangerous ${ }^{[22]}$. The legalisation of euthanasia could disturb the relationship of patient with health care staff because those who are assigned to provide care will have also the right to kill ${ }^{[23]}$.

\section{Medical opinions}

In the past, either doctor or scientific union could not accept euthanasia as way of resolving incurable illness. However, a medical dilemma that begins to emerge more often, today, is the benefit of cardio-respiratory resuscitation of patients with incurable diseases, especially in the final stage. Medical deontology plays a significant role because it includes the basic rules of behaviour from which doctors will be inspired and they need to follow these rules in a legal and social frame ${ }^{[24]}$.

\section{Nursing opinions}

From the Nightgale period until today, nurses aim to provide the best care to patients. In most countries, as in Greece, the professional rights of nurses report that the duty of the nurse is 'to provide support and care, before and after death, to patients and to their families' ${ }^{[25]}$. This statement is contrary to the definition of euthanasia. It is important, however, to mention that the nurse is an employee and has certain obligations toward nursing institution that works. Consequently, the refusal of nursing care can have repercussions on the nurse ${ }^{[18]}$. As an example, in countries that allow euthanasia, if a doctor decides to administer euthanasia, what the nurse will do?

\section{Nursing approach in euthanasia}

Death is an inevitable part of life. Nurses should be well educated so that they provide quality care to their dying patients. Nursing is the only health care team that provides 24 hours bedside care and thus, can observe and intervene when necessary ${ }^{[22]}$. Consequently, nurses should possess critical thinking abilities, observation skills and knowledge of nursing science. Nevertheless, there are important questions concerning the nurse and the dying patient: Is the nurse well prepared to care for the dying patient? How much the working conditions help to achieve this aim? Research in Greece has shown that health care professionals are not well prepared, from pre-registration nursing education, to face the subject of euthanasia ${ }^{[26]}$. The nursing education in Greece is focused on the confrontation of illness, avoiding issues such as decision-making and critical thinking.

In countries where euthanasia is currently legal, palliative care nurses have an increased scope of practice and responsibilities in working with these patients and their families ${ }^{[27]}$. These nurses have a very important role, which is not simply limited to assist the doctor while they are administering life-terminating drugs. The nurse's involvement begins when the patient requests to be euthanized and ends by supporting the patient's relatives, as well as the health care team after a potential life-terminating procedure ${ }^{[28]}$. It is important for them to be open minded, use palliative techniques, such as pain management, and to understand the context of the patient's decision-making process.

During the act of euthanasia, the nurse needs to assist the patient, their family and the physician by being present, even if they do not agree with the patient's decision ${ }^{[29]}$. Because nurses have a unique relationship with the patient, they are in a 
key position to provide these patients with valuable care. Nursing education needs to include specific training on how to support and assist patients and their families in the areas of counseling and end of life care.

\section{Nursing dilemmas for euthanasia}

End-of-life care is challenging; discussion around the subject of death can be fraught with difficulties and anxieties ${ }^{[30]}$. Patients request euthanasia for reasons relating to life experiences, not just medical problems ${ }^{[31]}$. Education is therefore vital. Nurses need skills in palliative care and communication. The World Medical Union in a congress in Madrid, in October 1987, condemned euthanasia stating that, even if it becomes after insistence a requirement of patients or relatives, it remains always a 'difficult decision'. The doctors said 'no' to euthanasia. Researches in Greece have shown that nurses also said 'no' to euthanasia. More precisely, Priami ${ }^{[26]}$ found that $40 \%$ of nurses disagreed in the acceleration of patients' death in the final stage of their lives, and Giakis and others ${ }^{[32]}$ report that $55.3 \%$ of nursing staff are against euthanasia.

There is no research involving Greek student nurses with regard to pre-registration knowledge and their opinions for euthanasia. Giakis and others ${ }^{[32]}$ have shown that the level of staff nurses' knowledge with regard to euthanasia is very low. It appears that nursing students are not well prepared to reflect on ethical dilemmas such as euthanasia. In nursing programs there are courses (nursing deontology, professional legislation, general psychology and counselling nursing) for students' preparation. It appears, however, that neither the courses nor the time are appropriate to discuss in depth issues such as euthanasia. Consequently, nurses are unable to have a complete and explicit view about euthanasia.

\section{Method}

The present research aimed to determine and compare the attitude of student nurses towards euthanasia. The study focused on three different levels of study (A', first semester/beginning, D', fourth semester/middle and Z', eight semester/students who are going to graduate) to determine whether the opinions of students are modified during their study.

Data were collected using a questionnaire with a total of 25 questions. In the first part, 12 general questions were included. Answers were developed using a 3-point scale (yes- no- I do not know). In the second part, we used a modified, reliable and valid questionnaire that was adopted by Frommelt ${ }^{[33,34]}$ 'Frommelt Attitude Toward Care of the Dying' (FATCOD). This questionnaire contains 30 questions with regard to the attitude of student nurses caring terminal patients. The questionnaire contains 5-point Likert scale (from strongly disagree to strongly agree).

According to Barrere et al. ${ }^{[35]}$ FATCOD has been used in 16 other countries, in 9 different languages, in addition to its use in 79 colleges/universities and healthcare systems in the United States. Particularly attention was given to translate the questionnaire. The forward-backward-forward translation technique was applied ${ }^{[36]}$. In the first step, two independent bilingual translators, with expertise in the field of nursing were involved in this step. They were citizens of Greece, native speakers of Greek, had lived in the United Kingdom and United States for more than 2 years. They translated the original English version of the questionnaire into Greek language. The first author was one of them.

A meeting involving the two independent bilingual translators conducted to review, reconcile and harmonize the forward translation. This reconciled forward translation was then translated back into English by another two independent bilingual translators who had not seen the source version of the FATCOD. The two independent translators were expertise in the field of nursing, were citizens of Greece, native speakers of Greek, who had passed the criterion for English competency (Proficiency); the fourth author was one of these. Researchers discussed the problematic items, and reached a consensus on the initial back-translated instrument.

Next, researchers, together with the forward translator reviewed and compared the backward translation with the original English questionnaire. The aim of this process was to reconcile the questionnaires by producing the final forward translation ${ }^{[36]}$. 
The main purpose of pre-testing the finalised translated questionnaire is to show whether all items are comprehensive and acceptable ${ }^{[36]}$. Initially, ten student nurses were involved in this step. All lived in Greece and were recruited by the first author. Researchers provided written informed consent, following procedures approved by an Institutional Review Board. Four of the student nurses were in A level (beginning), three were in D level (middle) and three in Z level (last year student). Six were girls and four were boys.

Participants were asked to read the instructions and complete the questionnaire carefully. After completing the questionnaire, a discussion was made regarding the content of the questions. Participants provided their opinions on how the wording of the items might be improved for clarity.

Researchers were deleted questions that first have almost the same meaning and second the content did not correspond to Greek reality. Following the above criteria, 17 questions were removed from which 12 questions coincided with the first criterion and 5 questions with the second criterion. Thus, 13 questions were used. Demographic characteristics were included related to age, sex, citizenship, educational institution and semesters.

\section{Sample}

A convenience sample of 599 students ( $80 \%$ responses) was drawn from two educational institutions and across all four years of study.

\section{Validity and reliability}

Content validity of a questionnaire was assessed by expert panel ${ }^{[7]}$. The expert panel focused in reviewing and deciding whether the wordings used in the translated questionnaire were appropriate.

The reliability of a questionnaire was examined by looking at the internal consistency. The Cronbach's alpha or scale reliability coefficient can be used to assess the internal consistency reliability ${ }^{[38]}$. A Cronbach's alpha of 0.70 is considered an acceptable reliability coefficient ${ }^{[39]}$. For the present study, the Cronbach's alpha was 0.75 .

\section{Procedure}

The research was approved by the Ethics Committee of both Institutions and letters were sent to Heads of Nursing Departments, asking permission to approach student nurses in A', D' and Z' semesters. Issues of anonymity, confidentiality and voluntary attendance were included in the letters. In order to approach a large number of students, authors decided to distribute the questionnaires in courses were students attendance was compulsory (nursing laboratories). The questionnaire was distributed to the students before courses begin. All students were asked to participate. Authors were present in order to inform students regarding the research and help answering questions. The time to complete the questionnaire ranged from 10 to 15 minutes.

\section{Statistical analysis}

The "rule of thumb" method was used for sample calculation. This means that with 25 questions we needed minimum of 50 students. After statistician advices, authors decided to increase sample size. The results were analysed using statistical program SPSS 19. Descriptive analysis (range, percentage, frequency, mean) and non-parametric test (Mann-Whitney U test) were used; significance was set at $p<.05$.

\section{Results}

The students' age ranged from 18 to 44 years (mean $=21$ years), was female $(81.1 \%)$, had Greek citizenship $(95.8 \%)$ and was from Technological Educational Institute (TEI) of Western Greece (52.3\%) (see Table 1). 
Table 1. Demographic characteristics of the sample

\begin{tabular}{ll}
\hline Age & $18-44, x=21$ years \\
Sex (n, \%) & Female $(486,81.1 \%)$, Male $(113,18.9 \%)$ \\
Citizenship (n, \%) & Greek $(574,95.8 \%)$, Other $(25,4.2 \%)$ \\
Educational Institute (n, \%) & TEI Western Greece $(313,52.3 \%)$, TEI Athens $(286,47.7 \%)$ \\
Semesters (n, \%) & A' semester $(214,35.7 \%), D^{\prime}$ semester $(196,32.7 \%)$ Z' semester $(189,31.6 \%)$ \\
\hline
\end{tabular}

\section{Part one}

Most student nurses (53\%) had little knowledge of euthanasia while it is important to report that this knowledge was not altered according to the duration of their study, in both institutions. Also, 54.4\% stated that the media was their main source of information, $15.4 \%$ stated scientific magazines and only $13.5 \%$ the nursing department. Most students (67\%) revealed that they did not know the nurses professional rights in Greece and whether they cover them in the process of euthanasia (91.2\%). Additionally, most students (52\%) did not agree with the application of euthanasia in terminally ill patients, and they would participate in euthanasia (67.6\%). Similarly, the vast majority of students $(80 \%)$ did not agree with application of euthanasia in children (below 15 years of age). Moreover, the majority of students report that the nursing education prepares them from 'few' to 'not at all' (63.3\%) for euthanasia. Most students did not agree with the legalisation of euthanasia (54.1\%), while they might participate where patients' conditions are unusually critical (43.6\%) (Coronary Care Units, Intensive Care Units, Oncology ward).

Table 2. Percentages (\%) of students opinions about how they would feel caring terminal-ill patient

\begin{tabular}{|c|c|c|c|c|c|}
\hline & Strongly Agree & Agree & Uncertain & Disagree & Strongly Disagree \\
\hline $\begin{array}{l}\text { I will feel uncomfortable speaking for } \\
\text { imminent death to terminal-ill patient }\end{array}$ & $205(34.2 \%)$ & $255(42.6 \%)$ & $85(14.2 \%)$ & $39(6.5 \%)$ & $15(2.5 \%)$ \\
\hline $\begin{array}{l}\text { I do not want to undertake the care of } \\
\text { terminal-ill patient }\end{array}$ & $41(6.8 \%)$ & $86(14.4 \%)$ & $191(31.9 \%)$ & $186(31 \%)$ & $95(15.9 \%)$ \\
\hline $\begin{array}{l}\text { I am afraid to be friend with a } \\
\text { terminal-ill patient }\end{array}$ & $14(2.3 \%)$ & $49(8.2 \%)$ & $105(17.5 \%)$ & $235(39.3 \%)$ & $196(32.7 \%)$ \\
\hline $\begin{array}{l}\text { The family of terminal-ill patient should } \\
\text { participate in his care }\end{array}$ & $390(65.1 \%)$ & $160(26.7 \%)$ & $35(5.8 \%)$ & $11(1.8 \%)$ & $3(0.6 \%)$ \\
\hline $\begin{array}{l}\text { I hope the patient that I care, will die } \\
\text { when I am not in shift }\end{array}$ & $46(7.7 \%)$ & $111(18.5 \%)$ & $167(27.9 \%)$ & $172(28.7 \%)$ & $103(17.2 \%)$ \\
\hline $\begin{array}{l}\text { While death is due, nurses should } \\
\text { withdraw their care in a terminal-ill } \\
\text { patient }\end{array}$ & $6(1 \%)$ & $16(2.7 \%)$ & $39(6.5 \%)$ & $164(27.4 \%)$ & $374(62.4 \%)$ \\
\hline $\begin{array}{l}\text { The terminal-ill patient should not } \\
\text { decide for his care }\end{array}$ & $27(4.5 \%)$ & $59(9.8 \%)$ & $105(17.5 \%)$ & $222(37.1 \%)$ & $186(31.1 \%)$ \\
\hline $\begin{array}{l}\text { It is beneficial for terminal-ill patient to } \\
\text { express his feelings }\end{array}$ & $359(59.9 \%)$ & $180(30.1 \%)$ & $31(5.2 \%)$ & $18(3 \%)$ & $11(1.8 \%)$ \\
\hline $\begin{array}{l}\text { The nursing care should include the } \\
\text { family of terminal-ill patient }\end{array}$ & $236(39.4 \%)$ & $246(41.1 \%)$ & $70(11.7 \%)$ & $28(4.7 \%)$ & $19(3.1 \%)$ \\
\hline $\begin{array}{l}\text { The terminal-ill patient and his family } \\
\text { should have an important role in } \\
\text { decision-making }\end{array}$ & $173(28.9 \%)$ & $193(32.2 \%)$ & $146(24.4 \%)$ & $70(11.7 \%)$ & $17(2.8 \%)$ \\
\hline $\begin{array}{l}\text { The sedative treatment should not be the } \\
\text { main concern when we care a } \\
\text { terminal-ill patient }\end{array}$ & $68(11.4 \%)$ & $173(28.9 \%)$ & $156(26 \%)$ & $134(22.3 \%)$ & $68(11.4 \%)$ \\
\hline $\begin{array}{l}\text { Nurses should provide sincere answers } \\
\text { to terminal-ill patient for his condition }\end{array}$ & $108(18 \%)$ & $203(33.9 \%)$ & $226(37.7 \%)$ & $51(8.6 \%)$ & $11(1.8 \%)$ \\
\hline $\begin{array}{l}\text { The teaching/education of families } \\
\text { regarding death, is not a nursing } \\
\text { competence }\end{array}$ & $26(4.3 \%)$ & $79(13.2 \%)$ & $107(17.9 \%)$ & $218(36.4 \%)$ & $169(28.2 \%)$ \\
\hline
\end{tabular}


We also asked students to rank what would influence their decision on attending to euthanasia, and students answered, patients decisions, family environment and personal believes as most important, while protocols and nurses professional rights considered as least important.

Most student nurses strongly agreed that patients' families should participate in their care, included in the nursing care plan and involved in patient decision-making. In addition, although the majority of students were not afraid to be friends with terminally patients, they were not sure if they would undertake their care. Moreover, most students believed that the teaching/education of families with regard to death is a nursing competence and patients should be able to express their feelings and worries to nursing staff. Finally, student nurses did not know whether nursing staff should give sincere answers to terminal patients and whether sedative treatment has a fundamental role in nursing care (see Table 2).

Finally, we used a non-parametric test to determine correlations between the demographic characteristics and the questions. In most tests, there were not statistically significance differences $(p>.05)$. However, we were found that the female students do not agree with the application of euthanasia $(Z=-3.696, p<.05)$, the patient family should participate in nursing care $(Z=-2.424, p<.05)$ and patients should express their feelings and worries $(Z=-2.056, p<.05)$. Also, students from TEI of Western Greece, were more in favour to undertake the care in terminal patient $(\mathrm{Z}=-5.458, p<.05)$ and are afraid less to be friends with terminal patient $(\mathrm{Z}=-2.301, p<.05)$.

\section{Discussion}

The issue of euthanasia is complicated, open and subject to debate in health sciences. Particularly today, nursing dilemmas are more complicated due to scientific progress that multiplies the possibilities of using knowledge and skills in a multidimensional ways ${ }^{[40]}$.

The results revealed that most student nurses in Greece had little knowledge of euthanasia, from first year to fourth year. Similar results found from Giakis and others ${ }^{[32]}$ that nursing staff have 'few' knowledge in euthanasia. It is true that nursing as autonomous and humanitarian science, requires not only scientific education/training and virtuosity, but also mental maturity and cultivated character in order to provide quality nursing care ${ }^{[20]}$.

It is also important to mention that the main source of information for students regarding euthanasia were the media. It appears that students were not well prepared with regard to moral dilemmas, from the pre-registration nursing education either because there are not enough courses or because the timeframe for the particular courses are not appropriate. Consequently, students are not learned, expressed opinions and questions about euthanasia. It is true that the theoretical courses about moral and ethical issues do not ensure that they will apply these rules/regulation to clinical practice ${ }^{[22]}$. It gives students, however, a stimulus to open horizons, sensitise their nursing conscience in order to view nursing profession as responsible service to people ${ }^{[41]}$.

In addition, the majority of students did not agree with the application of euthanasia in terminally ill patients and its legalisation in Greece. Probably, the religious element in Greece, that is intense, influences students' attitudes. More precisely, the church has supported, and even taught that the difficulties of life are a test for all people.

Interestingly, the vast majority of student nurses (91.2\%) did not know if nurses' professional rights cover them in a process of euthanasia. Here, it emerges some questions: Why students, and particularly graduates, do not know the nurses professional rights? How they will provide nursing care when they do not know the limits of clinical nursing practice? Although significant changes have been occurred in nursing education and clinical practice in Greece, nurses' professional rights have remained general, unclear and incomplete. It is true that if nurses' roles are extended, it will increase their legal responsibilities. 
In contrast to the past, nurses today can autonomously estimate, apply and evaluate the outcomes of nursing care and realise their responsibilities. Thus, nurses need clear and explicit professional rights in order to apply their scientific knowledge and skills in their clinical practice ${ }^{[42]}$. It is true that one of the most important roles of nurses is to offer continuous and appropriate nursing care to individuals, especially in the last phase of their lives. Nevertheless, student nurses revealed that they would feel uncomfortable speaking for imminent death to terminal-ill patients. Interestingly, this attitude did not change at the duration of their study. The above attitude of student nurses shows the bio-medical model that is predominated in Greek hospitals. In other words, doctors have the information and educational role for patients and their relatives.

Finally, families play an important role in the therapeutic care of patients. The majority of students agreed that the family should participate in patient care, be informed and participated in decisions regarding euthanasia. Also, the majority of the sample believed that the family should include in the nursing care. The nursing process should include the family (relatives and friends) and supporting effective contacts between the patient and his relatives ${ }^{[34]}$.

The first limitation of research was the small sample size from two institutions in Greece. Although the research offered important information for the attitude of student nurses in euthanasia during their study, it is necessary the utilisation of bigger sample in the future.

\section{Recommendations for practice}

It is true that good nursing care, especially end of life care, requires not only knowledge, skills, guidelines or protocols but also critical reflection and creativity. Nurses should have the opportunity to reflect on ethical dilemmas, focusing on their own attitudes, knowledge and care practice. In other words, professional nursing practice requires an environment where nurses knowledge, attitudes, and professional rights are coexisted to achieve patient well-being. However hospital environment, sometimes, could work as a barrier to ethical practice because the organisation philosophy may be different from nurses (personal) attitude. Nurses could be able to stimulate through education and their professional rights to reflect on ethical dilemmas. Moreover, nurses need personal and professional empowered in order to be able to implement difficult personal ethical decisions in euthanasia.

\section{Conclusions}

The issue of euthanasia constitutes a big challenge for all nurses in Greece. Based on the results, we assume that the enrichment of nursing curriculum (add courses and teaching hours) with subjects regarding moral dilemmas will be helpful to students. In addition, the need of continuing education for nurses at the duration of their career (seminars, conferences, postgraduate studies) seems to be necessary in order for nurses to practice safely and effectively. Last but not least, nurse's professional rights in Greece must be revised so that nurses is more explicit to decide about moral dilemmas, such as euthanasia.

\section{References}

[1] Drosou, B., and Kotrotsou, S. Euthanasia and Health Sciences. $26^{\circ}$ National Nursing Conference, 1999: Corfu, Greece.

[2] Appel, J.M. Neonatal Euthanasia: Why Require Parental Consent? Journal of Bioethical Inquiry. 2009 ; 6 (4): $477-482$. http://dx.doi.org/10.1007/s11673-009-9156-3

[3] Karlsson, M., Strang, P., \& Milberg, A. Attitudes toward euthanasia among Swedish medical students. Palliative Medicine. 2007; 21(7): 615-622. PMid:17942500 http://dx.doi.org/10.1177/0269216307081940

[4] Leo, A., \& Spathonis, G. Suicide and euthanasia in late life. Aging Clinical and Experimental Research. 2003; 15(2): 99-110. PMid:12889840 http://dx.doi.org/10.1007/BF03324486

[5] Evaggelou, I. Historical background of euthanasia: from ancient Greece up-to-date. Eletherotipia. 2001; 16(1): 4-5. 
[6] Keown, D., \& Keown, J. Killing, karma and caring: euthanasia in Buddhism and Christianity. Journal of Medical Ethics. 1995; 21: 265-269. PMid:8558539 http://dx.doi.org/10.1136/jme.21.5.265

[7] Dobscha, SK., Heintz, RT., Press, N., \& Ganzini, L. Oregon physicians' responses to requests for assisted suicide: A qualitative study. Journal of Palliative Medicine. 2004; 7(3): 451-461. PMid:15265355 http://dx.doi.org/10.1089/1096621041349374

[8] Quill, T., \& Arnold, RM. Evaluating requests for hastened death. Journal of Palliative Medicine. 2008 ; 11(8): $1151-1152$. PMid:18980457 http://dx.doi.org/10.1089/jpm.2008.9848

[9] Wreen, M. The Definition of Euthanasia. Philosophy and Phenomenological Research. 1988; 48 (4): 637-640. http://dx.doi.org/10.2307/2108012

[10] Wilkinson, J. The ethics of euthanasia. Palliative Medicine. 1990; 4 (2): 81-86. http://dx.doi.org/10.1177/026921639000400204

[11] Martien, T., Muller, MA., Pijnenborg, L., Bregje, D., van der Wal, G., \& van Eijk, J. The role of the nurse in active euthanasia and physician-assisted suicide. Journal of Advanced Nursing. 1997; 26(2): 424-430. http://dx.doi.org/10.1046/j.1365-2648.1997.1997026424.x

[12] Kitchener, B. Nurse characteristics and attitudes to active voluntary euthanasia: a survey in the Australian Capital Territory. Journal of Advanced Nursing. 1998; 28(1): 70-76. http://dx.doi.org/10.1046/j.1365-2648.1998.00775.x

[13] Parpa, E., Mystakidou, K., Tsilika, E., Sakkas, P., Patiraki, E., Pistevou-Gombaki, K., Govina, O., et al. Euthanasia and physician-assisted suicide in cases of terminal cancer: the opinions of physicians and nurses in Greece. Medicine, Science and Law. 2008; 48 (4): 333-341. http://dx.doi.org/10.1258/rsmmsl.48.4.333

[14] Stolberg, M. Active Euthanasia in Pre-Modern Society: Learned Debates and Popular Practices. Social History of Medicine. 2007; 20 (2): 206-207. http://dx.doi.org/10.1093/shm/hkm034

[15] Garity, J. Ethics Column: Relationship of the ANA Code of Ethics to Nurses' Collaborative Efforts. OJIN: The Online Journal of Issues in Nursing. 2005; 10(3). Available from:

http://www.nursingworld.org/MainMenuCategories/ANAMarketplace/ANAPeriodicals/OJIN/TableofContents/Volume102005/ No3Sept05/CodeofEthicsRelationship.html

[16] Burt, A. The Supreme Court speaks-not assisted suicide but a constitutional right to palliative care. New England Journal of Medicine. 1997; 337: 1234-1236. PMid:9337388 http://dx.doi.org/10.1056/NEJM199710233371712

[17] Monagle, J., \& Thomasma, D. Health care ethics: Critical issues for the $21^{\text {st }}$ century. Au Aspen Publication: GaithersburgMaryland, 1998.

[18] Giannopoulou, C. Dilemmas and problem-solving in modern nursing. H Tavitha: Athens, 2003.

[19] Greek Ministry of Health. Euthanasia and health professionals. Ministry of Health: Athens, 2004.

[20] Sapountzi-Krepia, D. Religious beliefs and spirituality in nursing care. Nosileftiki. 2002; 41 (4): 365-370.

[21] Milionis, N. Euthanasia and cancer. Iatriki. 2000; 5: 97-105.

[22] Lemonidou, C. Research regarding the nursing ethical code and dilemmas in Greece. Nosileftiki. 2003; 42(2): $150-156$.

[23] Gillon, R. Principles of health care ethics. Willey: New York, 1994.

[24] Asai, A., Miura, Y., Tanabe, N., Kurihara, T., \& Fukuhara, S. Advance directives and other medical decisions concerning the end of life in cancer patients in Japan. European Journal of Cancer. 1998; 34: 1582-1586. http://dx.doi.org/10.1016/S0959-8049(98)00148-8

[25] Hellenic Nurses Association. The Professional Rights of Nurses. Hellenic Nurses Association: Athens, 2004.

[26] Priami, M. Attitudes of nursing staff about euthanasia. Nosileftiki. 2001; 40 (4): 43-50.

[27] Georges, J., Grypdonck, M., Dierckx, B., \& Casterle, D. Being a palliative care nurse in an academic hospital: a qualitative study about nurses' perceptions of palliative care nursing. Journal of Clinical Nursing. 2002; 11(6): 785-793. PMid:12427184 http://dx.doi.org/10.1046/j.1365-2702.2002.00654.x

[28] van Bruchem, A., van Wijmen, F., Huijer, AS., \& ter Meulen, R. Dutch Nurses' Attitudes Towards Euthanasia and Physician-Assisted Suicide. Nursing Ethics. 2008; 15(2): 186-198. PMid:18272609 http://dx.doi.org/10.1177/0969733007086016

[29] Quaghebeur, T., Dierckx de Casterlé, B., Gastmans, C. Nursing and Euthanasia: a Review of Argument-Based Ethics Literature. Nursing Ethics. 2009; 16 (4): 466-486. PMid:19528103 http://dx.doi.org/10.1177/0969733009104610

[30] Ray, R., Raju, M. Attitude towards euthanasia in relation to death anxiety among a sample of 343 nurses in India. Psychological Reports. 2006; 99 (1): 20-26. PMid:17037446 http://dx.doi.org/10.2466/pr0.99.1.20-26

[31] Ezekiel, E. The history of euthanasia debates in the United States and Britain. Annals of Internal Medicine. $1994 ; 121$ (10): 796.

[32] Giakis, N., Merkouris, A., Polichronopoulou, E., \& Adali, A. The attitude of nursing staff about euthanasia. Nosileftiki. 2005; 44(1): 84-91.

[33] Frommelt, M. The effects of death education on nurses' attitudes toward caring for terminally ill persons and their families. American Journal of Hospice and Palliative Care. 1991; 8(5): 37-43. http://dx.doi.org/10.1177/104990919100800509 
[34] Frommelt, M. Attitudes toward care of the terminally ill: an educational intervention. American Journal of Hospice and Palliative Care. 2003; 20(1): 13-22. http://dx.doi.org/10.1177/104990910302000108

[35] Barrere, CC., Durkin, A., \& LaCoursiere, S. The influence of end-of-life education on attitudes of nursing students. International Journal of Nursing Education. 2008; 5(1): 1-18.

[36] Brislin, RW. Back-translation for cross-cultural research. Journal of Cross-Cultural Psychology. 1970; 1(3): $185-216$. http://dx.doi.org/10.1177/135910457000100301

[37] Carmines, EG., \& Zeller, RA. Reliability and viability assessment. Thousand Oaks: Sage, 1991.

[38] Bland, JM., \& Altman, DG. Statistical methods for assessing agreement between two methods of clinical measurement. Lancet. 1986; 327 (8476): 307-310. http://dx.doi.org/10.1016/S0140-6736(86)90837-8

[39] Burns, N., \& Grove, G. Nursing Research. WB Saunders: Philadelphia, 1987.

[40] Asch, DA., \& Dekay, ML. Euthanasia among US critical care nurses: practices, attitudes and social and professional correlates. Medical Care. 1997; 35: 890-900. PMid:9298078 http://dx.doi.org/10.1097/00005650-199709000-00002

[41] Gula, R. Euthanasia: moral and pastoral perspectives. Paulist Press: New York, 1994.

[42] Bampatsikou, F. The value of clinical practice to the preparation of student nurses. Nosileftiki. 2001; 40 (4): 76-80. 